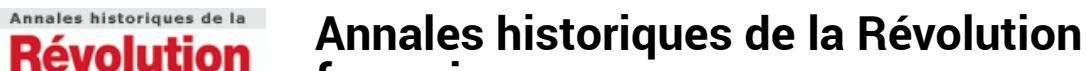

française française

371 | janvier-mars 2013

Robespierre

\section{Yves PIERRONNE, Vivre en banlieue sous la Révolution}

Aix-en-Provence, Éditions Persée, vol. 1, (1787-1791), 2011, 180 p., ISBN

978-2-35216-843-0, $15 €$; vol. 2, (1792-96), 2012, 360 p., ISBN

978-2-8231-0172-0, 22,30€.

\section{Serge Bianchi}

\section{OpenEdition \\ Journals}

\section{Édition électronique}

URL : https://journals.openedition.org/ahrf/12726

DOI : 10.4000/ahrf.12726

ISSN : 1952-403X

\section{Éditeur :}

Armand Colin, Société des études robespierristes

\section{Édition imprimée}

Date de publication : 1 mars 2013

Pagination : 206-208

ISBN : 978-2-200-92824-7

ISSN : 0003-4436

\section{Référence électronique}

Serge Bianchi, «Yves pierRonne, Vivre en banlieue sous la Révolution », Annales historiques de la Révolution française [En ligne], 371 I janvier-mars 2013, mis en ligne le 19 avril 2013, consulté le 01 juillet 2021. URL : http://journals.openedition.org/ahrf/12726 ; DOl : https://doi.org/10.4000/ahrf.12726

Ce document a été généré automatiquement le 1 juillet 2021.

Tous droits réservés 


\title{
Yves PIERRONNE, Vivre en banlieue sous la Révolution
}

\author{
Aix-en-Provence, Éditions Persée, vol. 1, (1787-1791), 2011, 180 p., ISBN \\ 978-2-35216-843-0, $15 €$; vol. 2, (1792-96), 2012, 360 p., ISBN \\ 978-2-8231-0172-0, 22,30€.
}

\section{Serge Bianchi}

\section{RÉFÉRENCE}

Yves PIERRONNE, Vivre en banlieue sous la Révolution, Aix-en-Provence, Éditions Persée, vol.

1, (1787-1791), 2011, 180 p., ISBN 978-2-35216-843-0, 15 € ; vol. 2, (1792-96), 2012, 360 p., ISBN 978-2-8231-0172-0, 22,30€.

1 Le 30 frimaire an IV (11 décembre 1795), la municipalité de Montrouge remet aux autorités de tutelle ce que Yves Pierronne qualifie de «lieux de mémoire du pouvoir municipal »: un portrait de Rousseau, une pierre de la Bastille, les registres de la municipalité, de la société populaire, les papiers de la garde nationale, du comité de surveillance, les archives de la fabrique, la comptabilité de la commune... Pour l'auteur, la longue parenthèse du pouvoir local, ouverte par la réforme de Brienne de 1787 auparavant initiée par Laverdy, Turgot et Calonne, se termine lorsque les municipalités de canton du Directoire remplacent les conseils élus par les citoyens actifs de chaque commune. Pendant huit années, on a pu assister dans la banlieue parisienne à la naissance et l'affirmation d'une " appropriation citoyenne de la vie locale ", au passage de la " paroisse à la commune ", un moment intense dans la décennie révolutionnaire que Yves Pierronne tente de faire revivre. Il le fait au moyen de quatre-vingt deux textes commentés, extraits de dépôts d'archives municipales d'une trentaine de communes de la "petite couronne » de Paris, situés dans les départements actuels des Hauts-de-Seine, de la Seine-Saint-Denis et du Val-de Marne. Enseignant-chercheur sur la période révolutionnaire depuis la fin des années 1980, l'auteur de ces deux volumes est particulièrement qualifié pour tenter ce pari ambitieux, à la suite de travaux 
universitaires relatifs à la commune d'Ivry-sur-Seine (maîtrise 1991), aux sociétés populaires du Val-de-Marne (DEA 1993), et de recherches originales sur les questions de la santé et de l'enseignement dans la banlieue parisienne. La fréquentation assidue des archives locales le conduit à proposer un florilège de textes de nature hétérogène en apparence, de simples faits de la vie quotidienne (un doigt coupé, un abus de boisson, deux noyades) à des «élans révolutionnaires " politiques, en passant par les problèmes des subsistances, de l'école, ou de la déchristianisation. Chaque texte, soigneusement retranscrit, daté et titré, est accompagné d'un commentaire précisant le contexte, les enjeux et (parfois) une interprétation. De Neuilly-sur-Seine à Montreuil, de Saint-Denis à Charenton, des municipalités mettent en scène leurs compétences et leurs pratiques, au fil de procès-verbaux de délibérations rédigés par des greffiers, souvent maîtres d'école ou instituteurs. La paroisse, aux pouvoirs partagés entre le seigneur, le subdélégué, le prévôt, le curé, le syndic, la fabrique, devient progressivement la commune, où le seul conseil municipal, élu au suffrage direct par les citoyens, se charge de l'ensemble des questions administratives, fiscales, de justice et de police locales, d'armement des civils... La fréquence des séances augmente entre 1790 et l'an II, avec les attributions de la commune, dans l'épisode de décentralisation le plus poussé de l'histoire du pays, avant les années 1980. Maire illettré, femmes victimes de violences conjugales, couple d'instituteurs rémunérés et intégrés au village, conflits sur les prix et les salaires, révoltes de la faim, épurations politiques, citoyenne " maitre de poste »... Les tranches de vie locale se succèdent, dans le style de l'époque, mêlant l'anecdote aux règlements de comptes politiques et sociaux.

2 Le lecteur peut être dérouté par la succession des quatre-vingt deux textes, classés par ordre chronologique, mais sans rapport logique apparent, faisant voyager le lecteur de Puteaux (dix textes) à Saint-Denis (huit textes), de Suresnes (cinq textes) à Vincennes (six textes). Un tel recueil de documents, aussi élaboré soit-il, appelle des compléments indispensables, dont la lecture des monographies locales qui se sont multipliées au moment du bicentenaire de la Révolution. Il mériterait également des fiches biographiques du personnel politique, à l'image du maire d'Ivry-sur-Seine, Renoult, dont le parcours politique, du "coq de village " d'Ancien Régime au «notable » du Consulat, est sans doute exemplaire à plus d'un titre. Le télescopage de textes, voulu par l'auteur, ne permet pas d'approfondir les questions de la politisation au village, ni des thèmes majeurs, telles la garde nationale ou les nuances de la déchristianisation. Yves Pierronne reste parfois proche du texte brut, n'en donne pas certaines clefs dont il dispose pourtant. Les spécialistes ne manqueront pas de discuter certains concepts ("sans-culottes montagnards»), certaines approches que des ouvrages récents ont éclairées. Mais l'essentiel n'est pas là.

Yves Pierronne centre ces deux volumes sur un domaine resté trop marginal des recherches en Révolution française, après l'élan du bicentenaire : celui de l'histoire du pouvoir local et de ses acteurs. Le sillon a été amorcé par des ouvrages pionniers, dont le Guide de l'histoire locale (Alain Croix, Didier Guivarch, 1990), La Révolution française et le monde rural (CTHS/INRA, 1989), Pouvoir local et Révolution (PUR, 1995), Les politiques de la Terreur (PUR, 2008). Il a été creusé par de nombreux travaux universitaires inédits, et des publications sur les Villages dans l'histoire (Francis Arzalier, 1996), Liberty and Locality in revolutionary France (Peter Jones, 2003), La conduite communale des affaires villageoises en Europe (Septentrion, 2012). Ces études montrent des villages évoluant au rythme de la séquence révolutionnaire, très éloignés du "village immobile» au XVIII ${ }^{e}$ siècle 
(Sennely en Sologne, 1972), comme d'un «éternel paysan » qui résisterait de manière univoque aux impulsions de la Révolution. L'élection d'un personnel politique et d'une garde nationale pléthoriques, la mise en place de sociétés populaires et de comités de surveillance en 1793-an II, la gestion municipale des affaires quotidiennes, des litiges de voisinages, des contestations familiales, des tensions communautaires: autant d'éléments qui éclairent l'entrée des villageois dans le régime républicain, leurs conquêtes, leurs contradictions et leurs résistances. Pour avoir tenté de préciser l'importance de La Première République au village (CTHS, 2003) dans deux cent-quarante villages et bourgs du sud de l'île-de-France et avoir souvent croisé les problèmes soulevés par les ouvrages d'Yves Pierronne, nous voudrions ici saluer leur utilité et leur originalité. Lors d'une gestion municipale à son (éphémère) apogée, la vie des villages devient un moment l'affaire du plus grand nombre, les luttes pour le pouvoir local croisent la grande histoire, avant que les municipalités de canton ne mettent fin en 1796 « à la période de démocratie locale commencée en 1789 ». Le recueil de documents proposé par Yves Pierronne, en apparence modeste, ouvre une voie dont pourraient s'inspirer les enseignants, par un ancrage local et quotidien susceptible d'intéresser les élèves des établissements secondaires et un lectorat citoyen. Dans une conjoncture où une certaine amnésie risque d'occulter la «révolution paysanne » mise en valeur par Georges Lefebvre et Anatoli Ado, entre autres auteurs, Vivre en banlieue sous la Révolution rappelle avec pédagogie et éclat que des villages et des bourgs proches de Paris ont connu, entre 1790 et 1795 , un niveau de participation, d'élections, de décentralisation, de politisation (et de résistances) exceptionnel, archives à l'appui, dans l'histoire de la France contemporaine. 